\title{
Peer Review of "Influence of the COVID-19 Lockdown on the Physical and Psychosocial Well-being and Work Productivity of Remote Workers: Cross-sectional Correlational Study"
}

\section{Laura Taraboanta, MS}

Click Therapeutics, New York, NY, United States

\section{Related Articles:}

Preprint (PsyArXiv): https://psyarxiv.com/dnuk3/

Authors' Response to Peer-Review Reports: https://med.jmirx.org/2021/4/e34609/

Published Article: https://med.jmirx.org/2021/4/e30708/

(JMIRx Med 2021;2(4):e34608) doi: 10.2196/34608

This is a peer-review report submitted for the paper "Influence of the COVID-19 Lockdown on the Physical and Psychosocial Well-being and Work Productivity of Remote Workers: Cross-sectional Correlational Study".

\section{Round 1 Review:}

\section{General Comments}

No major comments to add. The overall design, analysis, and conclusion [1] present a critical view into the impact of the
COVID-19 pandemic on remote workers in the UK and help facilitate broader conversations on how to continue to track physical and psychological metrics as restrictions are easing. Additionally, the paper offers recommendations on how employers and government policy and guidelines can best support overall well-being and productivity by looking at the data and seeing where the unmet needs are. A follow-up study would be interesting with the same participants, tracking them over the span of 1 year to 18 months and assessing the same metrics to look for any change in the scores (improvements, further decline, etc).

\section{Conflicts of Interest}

None declared.

\section{Reference}

1. Tronco HYA, Parente F, Faghy MA, Roscoe CMP, Maratos FA. Influence of the COVID-19 lockdown on the physical and psychosocial well-being and work productivity of remote workers: cross-sectional correlational study. JMIRx Med 2021 [FREE Full text] [doi: 10.2196/30708]

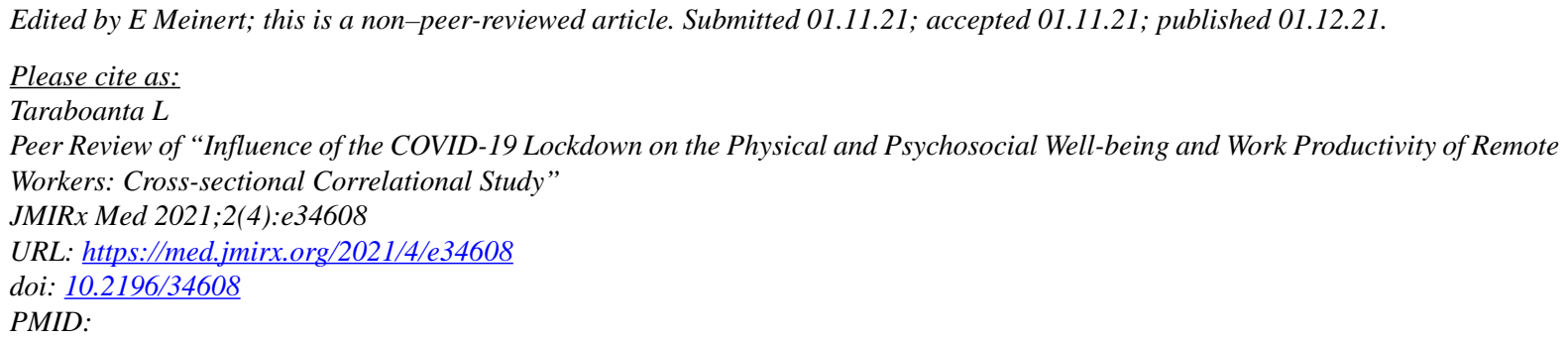

CLaura Taraboanta. Originally published in JMIRx Med (https://med.jmirx.org), 01.12.2021. This is an open-access article distributed under the terms of the Creative Commons Attribution License (https://creativecommons.org/licenses/by/4.0/), which permits unrestricted use, distribution, and reproduction in any medium, provided the original work, first published in JMIRx Med, is properly cited. The complete bibliographic information, a link to the original publication on https://med.jmirx.org/, as well as this copyright and license information must be included. 